\title{
Effect of Sulfur-Containing Primers for Noble Metals on the Bond Strength of Self-Cured Acrylic Resin
}

\author{
Keiichi Yoshida \\ Clinic of Fixed Prosthodontics, Nagasaki University Hospital, 1-7-1, Sakamoto, Nagasaki 852-8588, Japan; \\ keiichi@nagasaki-u.ac.jp
}

Received: 5 April 2017; Accepted: 15 June 2017; Published: 20 June 2017

\begin{abstract}
This study investigated the effect of sulfur-containing primers for noble metals on the shear bond strength of self-cured acrylic resin after thermal cycling (TC). Four pure metals ( $\mathrm{Au}, \mathrm{Ag}, \mathrm{Cu}$, and $\mathrm{Pd}$ ) and type IV Au alloy were either untreated, or treated with one of the five sulfur-containing metal primers (V-Primer, Metaltite, Alloy Primer, Metal Link Primer, and Metal Primer Z). Afterwards, a brass ring was placed on the metal surface and filled with self-cured acrylic resin $(n=10)$. The bond strengths were measured after $24 \mathrm{~h}$ (TC0) and after 2000 thermal cycles at $4-60^{\circ} \mathrm{C}$ (TC2000). Three-way ANOVA and Tukey compromise post hoc tests were used to analyze the data $(\alpha=0.05)$. All of the sulfur-containing primers significantly improved the resin bond strength as compared to that of the non-primed group at TC0 regardless of the metal type $(p<0.05)$. However, at TC2000, the bond strengths between the resin and the five metals significantly decreased with respect to the values obtained at TC 0 regardless of the primer $(p<0.05)$. The sulfur-containing metal primers, except for Metal Link Primer, were found to be more effective for improving the bond strength between the self-cured acrylic resin and Ag as compared to the other three pure metals $(p<0.05)$. The bond strengths between the resin and Au and type IV Au alloy at TC2000 were the highest ones when Metal Primer Z was used.
\end{abstract}

Keywords: bond strength; metal primer; noble metal; sulfur-containing; thermal cycling

\section{Introduction}

Metal crowns and fixed partial dentures (often fabricated from noble metals) are widely used as functional restorations for posterior teeth. Since the strong and durable bonding of resin luting cements to metal surfaces is extremely important for restorations, their adhesion to base metals and enamel substrates can be effectively improved using carboxylic or phosphate promoting monomers [1]. However, these functional monomers were found to be inefficient for noble metal alloys [2]. Therefore, various surface treatment methods have been developed for noble metals, including electrolytic Sn-plating [3-7], high-temperature oxidation [8], the application of a liquid Ga-Sn alloy [9], and silica coating [10]. In addition, sulfur-containing monomers for bonding resins to noble metal alloys were synthesized as alternatives to these techniques [11,12], and marketed as commercially available metal primers. These monomers contain 6-(4-vinylbenzyl-n-propyl) amino-1,3,5-triazine-2,4-dithiol (VBATDT) [13], thiophosphoric acid derivatives (MEPS) [14,15], 6-methacryloyloxyhexyl 2-thiouracil-5-carboxylate (MTU-6) [16], or 10-methacryloyloxydecyl-6,6-dithiooctanate (MDDT) [17], and their single-liquid primers can be easily applied onto noble metal surfaces without special equipment or complicated surface treatment procedures. It has been also reported that the sulfur-containing monomers promoted the adhesion between the resin and pure metals, such as $\mathrm{Au}, \mathrm{Ag}, \mathrm{Cu}$, and Pd $[12,13]$. The sulfur-containing monomers contained in commercially available metal primers were effective for improving the bond strength of resin to noble alloys [18-21]. However, particular types of the sulfur-containing metal primers that result in the most durable bonding between the resin and the metal elements of gold alloys still remain unknown. 
The purpose of this study was to determine the most effective sulfur-containing metal primers for improving the bonding durability of self-cured acrylic resin to pure $\mathrm{Au}, \mathrm{Ag}, \mathrm{Cu}$, and $\mathrm{Pd}$, which represent the elements of type IV gold alloy. To achieve this goal, the bond strength and bonding durability of self-cured acrylic resin to the four pure metals and type IV Au alloy were evaluated using six different sulfur-containing metal primers.

\section{Materials and Methods}

The descriptions of the four pure metals and type IV Au alloy, five commercially available sulfur-containing metal primers and one experimental sulfur-containing primer, and self-cured acrylic resin investigated in this study are given in Table 1 . The chemical structures of the monomers contained in the metal primers are shown in Figure 1.

Table 1. Materials used in the study.

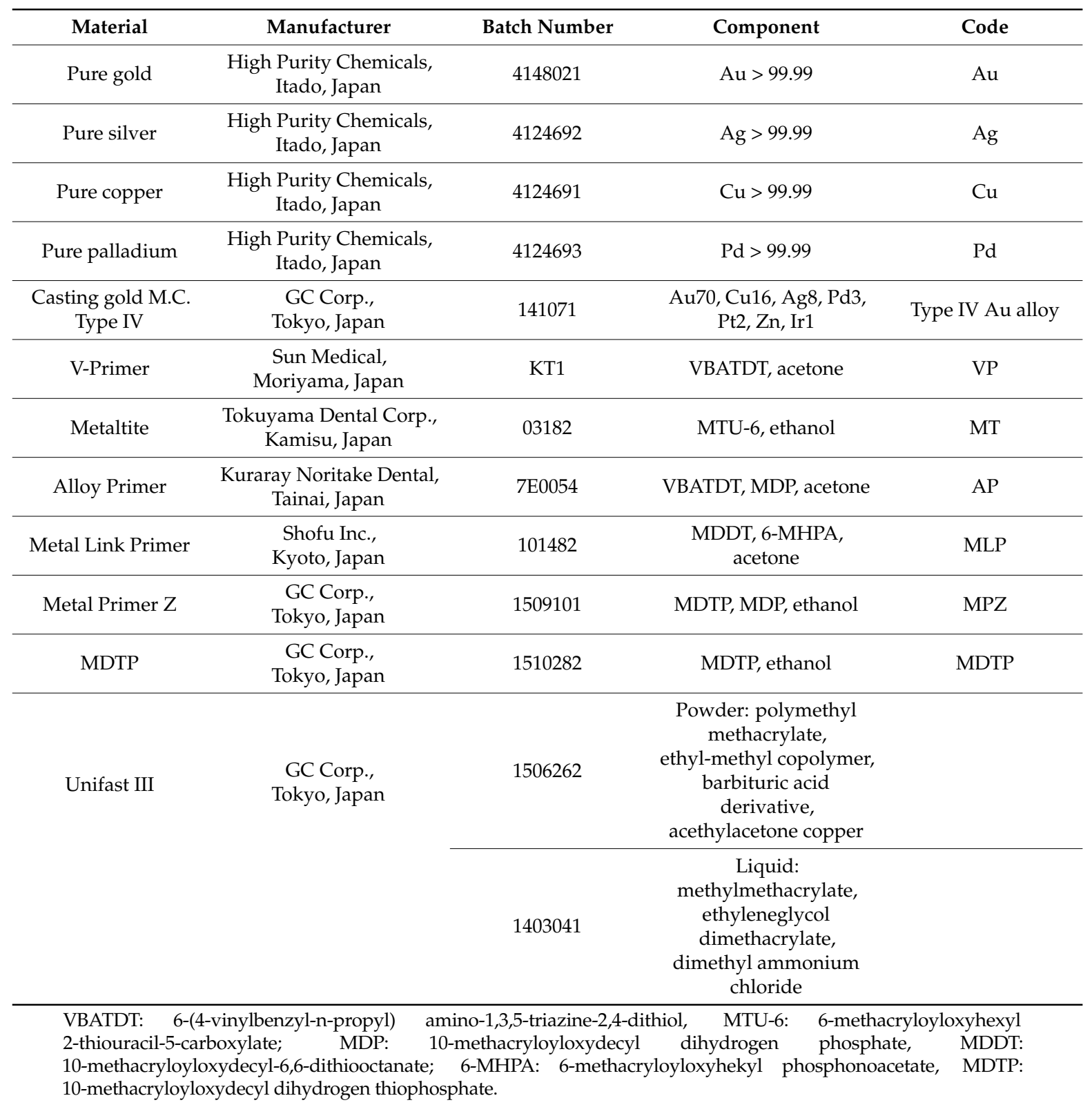


<smiles>C=Cc1ccc(CN2N=C(S)NC(=S)N2)cc1</smiles>

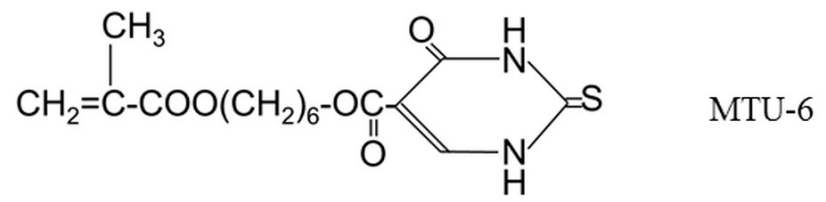<smiles>C=C(C)C(=O)OCCOC(=O)CC1CCSS1</smiles><smiles>C=C(C)C(=O)OCCOP(O)(O)=S</smiles>

MDTP<smiles>C=C(C)C(=O)OCCOP(=O)(O)O</smiles>

MDP<smiles>C=C(C)C(=O)OCC(=O)OCC(=O)O</smiles>

6-MHPA

Figure 1. Chemical structures of four sulfur-containing monomers and two phosphoric acid monomers.

\subsection{Preparation of Bonding Specimens}

Disk metal specimens $(8.0 \mathrm{~mm}$ in diameter, $2.0 \mathrm{~mm}$ in thickness) of the four pure metals were supplied by the manufacturer, while the disk specimens of type IV Au alloy with the same dimensions were cast according to the manufacturer's instructions. The surfaces of all bonding metal specimens were polished with \#1000 Si carbide paper (Marumoto Struers Co., Ltd, Tokyo, Japan), followed by ultrasonic cleaning for $10 \mathrm{~min}$ in distilled water and subsequent drying with oil-free air for $5 \mathrm{~s}$.

The bonding surfaces were primed with one of the six sulfur-containing metal primers using a sponge microbrush, and then dried with oil-free air for $5 \mathrm{~s}$. Pieces of polyethylene adhesive tape (approximately $50 \mu \mathrm{m}$ in thickness) with 4.0-mm-diameter circular holes were placed on the pretreated surfaces of the metal specimens to define the bonding area. A brass ring $(5 \mathrm{~mm}$ inner diameter, $7 \mathrm{~mm}$ outer diameter, and $2 \mathrm{~mm}$ thickness) was placed on the tape top, and then filled with self-cured acrylic resin using a brush-on technique. The non-primed specimens were also prepared for each of the five metals in the same manner (None). The bonded specimens were stored at a room temperature of $22 \pm 2{ }^{\circ} \mathrm{C}$ for $30 \mathrm{~min}$.

Each specimen group was divided into two subgroups $(n=20)$, corresponding to two different storage conditions. One subgroup $(n=10)$ was stored in distilled water at $37^{\circ} \mathrm{C}$ for $24 \mathrm{~h}$, while the other subgroup $(n=10)$ was subjected to 2000 thermal cycles (TC) between two different water baths (Rika-Kogyo, Hachioji, Japan) maintained at $4{ }^{\circ} \mathrm{C}$ and $60^{\circ} \mathrm{C}$; the dwelling time in each bath was $1 \mathrm{~min}$. 


\subsection{Shear Testing Procedure}

Each bonded specimen was embedded in an acrylic resin mold, and then placed inside an ISO/TR 11405 shear tests jig. The shear bond strengths were measured using a universal testing machine (AGS-10kNG, Shimazu Corp., Kyoto, Japan), with a load applied in the direction parallel to the bonding surface at a crosshead speed of $0.5 \mathrm{~mm} / \mathrm{min}$ (Figure 2). The shear bond strength was calculated by dividing the force, at which bond failure occurred, by the bonding area.

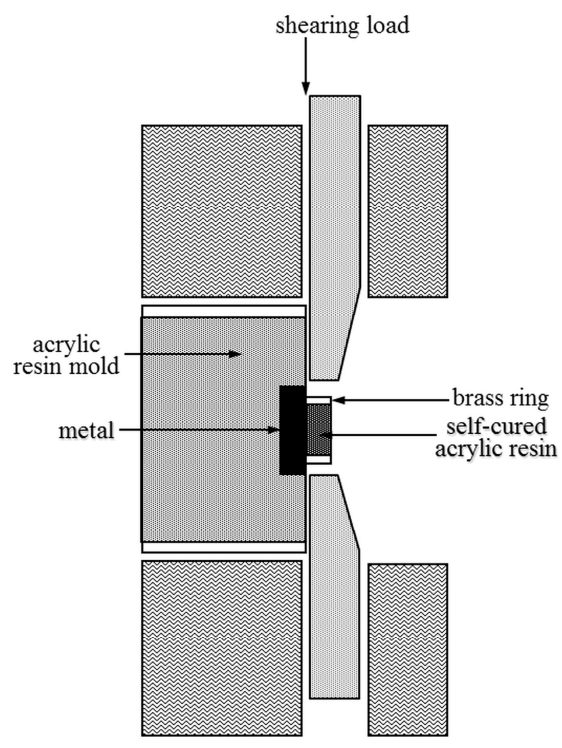

Figure 2. Shear test configuration.

The debonded surfaces were examined with an optical microscope (SMZ-10, Nikon Corp., Tokyo, Japan) at a magnification of $\times 45$ to evaluate possible failure types. The observed failure modes were classified as either (i) an adhesive failure at the metal-acrylic resin interface, or (ii) a mixed failure of an adhesive failure at the metal-acrylic resin interface and a cohesive failure of the acrylic resin.

\subsection{Statistical Analysis}

SPSS 17.0 (SPSS Inc., Chicago, IL, USA) was used to analyze the results of bond strength measurements. Three-way ANOVA tests were performed for the obtained bond strength values in order to determine the effects produced by the metal types, different metal primers, and thermal cycles. Multiple comparisons of the means were conducted using the post hoc Tukey compromise test to identify any significant differences among the groups $(p<0.05)$.

\subsection{X-Ray Photoelectron Spectroscopy (XPS)}

An additional type IV Au alloy specimen was analyzed by XPS measurements, which were performed using a spectrometer (ULVAC-PHI, Inc., 5701LSci, Chigasaki, Japan) equipped with a $2.0 \mathrm{~mm} \times 0.8 \mathrm{~mm} \mathrm{Al} \mathrm{X-ray} \mathrm{source.} \mathrm{The} \mathrm{take-off} \mathrm{angle} \mathrm{between} \mathrm{the} \mathrm{specimen} \mathrm{surface} \mathrm{and} \mathrm{the} \mathrm{electron}$ optical axis of the spectrometer was maintained at $50^{\circ}$.

\section{Results}

The shear bond strength results failed a test of the homogeneity of variance $(p<0.001)$. However, this was resolved by a square root transformation when sufficient homogeneity was achieved $(p=0.0642)$. The results of three-way ANOVA on the transformation data (Table 2) showed that the effects of the metal primer, metal type, and thermal cycling procedure on the bond strength were statistically significant, and their interactions were also significant $(p<0.0001)$. The mean values, 
standard deviations in parentheses, and significant differences of the shear bond strengths between the self-cured acrylic resin and five metals obtained at TC0 and TC2000 are listed in Table 3 and graphically presented in Figure 3.

Table 2. Three-way ANOVA results for shear bond strength transformed to square root.

\begin{tabular}{cccccc}
\hline Source & Sum of Squares & df & Mean Square & F & $p$ \\
\hline Noble Metal (A) & 188.4872 & 4 & 47.1218 & 655.1361 & $<0.0001$ \\
Metal primer (B) & 382.1956 & 6 & 63.6993 & 899.1314 & $<0.0001$ \\
Thermal cycling (C) & 867.3237 & 1 & 867.3237 & $12,242.4948$ & $<0.0001$ \\
A $\times$ B & 260.1635 & 24 & 10.8401 & 153.0114 & $<0.0001$ \\
A $\times$ C & 10.3560 & 4 & 2.5890 & 36.5445 & $<0.0001$ \\
B $\times$ C & 26.1581 & 6 & 4.3597 & 61.5381 & $<0.0001$ \\
A $\times$ B $\times$ C & 32.4949 & 24 & 1.3540 & 19.1114 & $<0.0001$ \\
Error & 44.6326 & 630 & 0.0708 & & \\
Total & 1811.8116 & 699 & & & \\
\hline
\end{tabular}
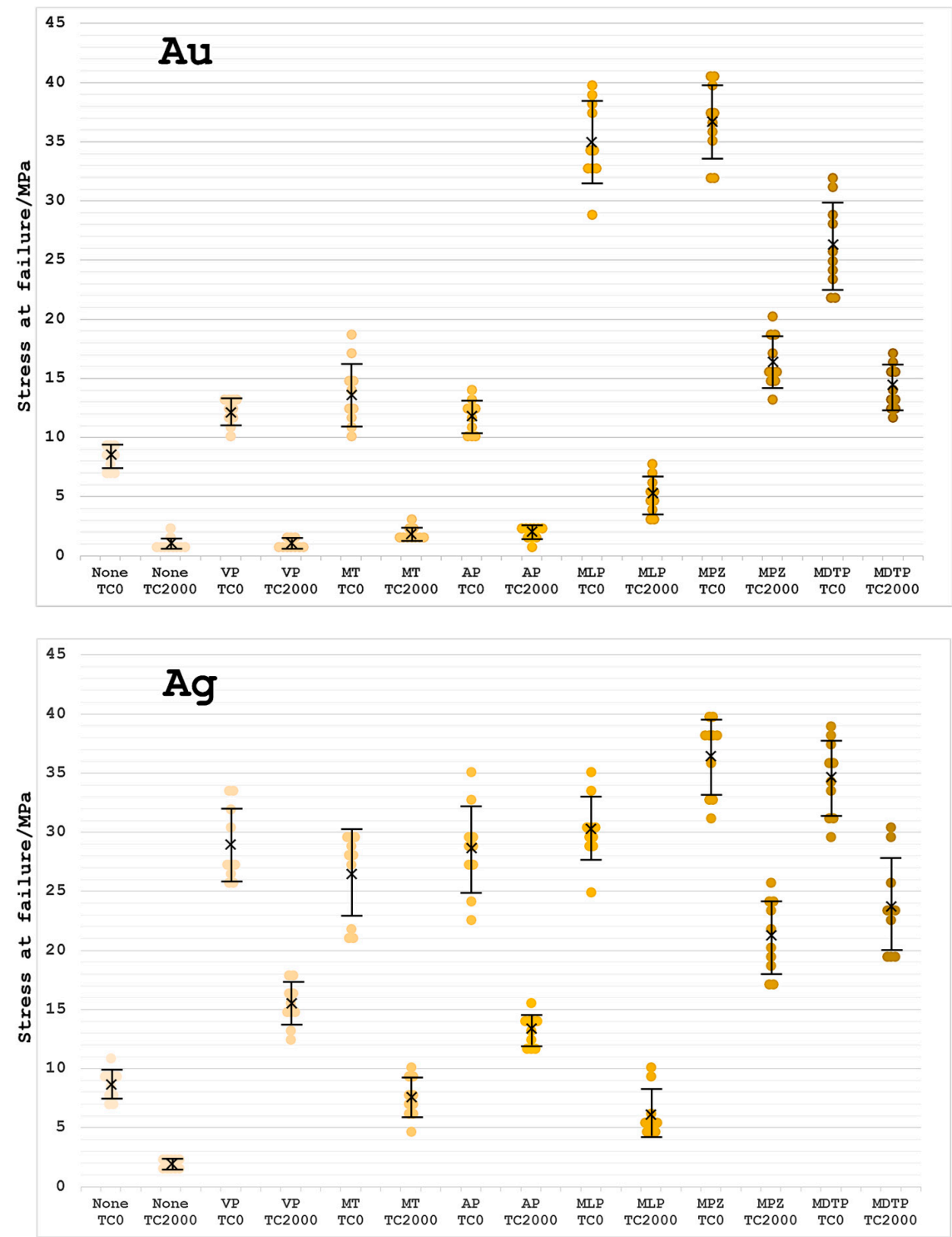

Figure 3. Cont. 

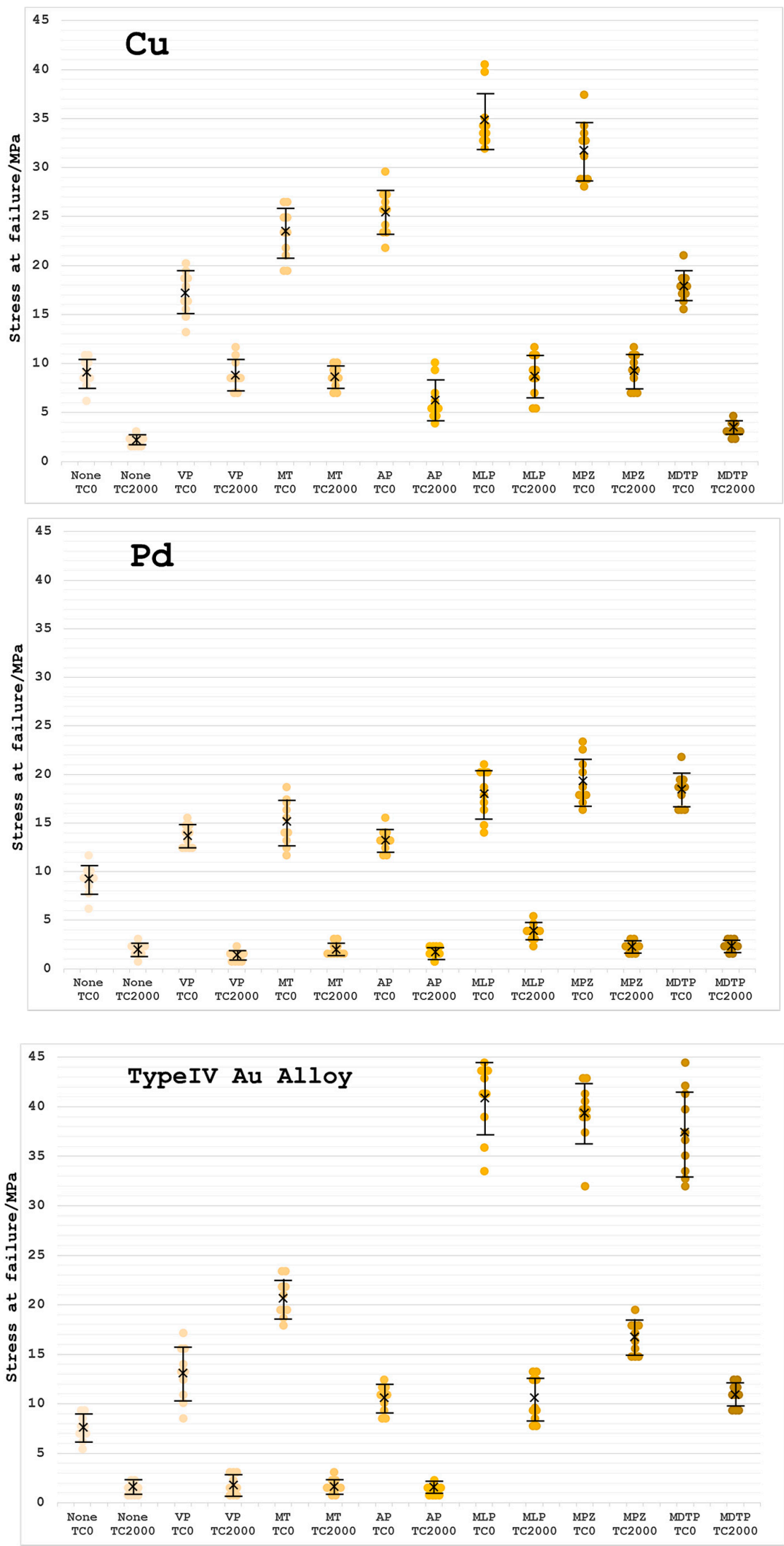

Figure 3. Every raw data point of each shear bond strength present in the scatter diagrams for each metal. The marked $\times$ represents the mean value and the error bar standard deviation. 
Table 3. Mean (SD in parenthesis) values of shear bond strength for test groups.

\begin{tabular}{|c|c|c|c|c|c|c|c|c|c|c|c|}
\hline \multirow{2}{*}{ Primer } & \multirow{2}{*}{$\begin{array}{l}\text { Metal } \\
\text { Cycles }\end{array}$} & \multicolumn{2}{|c|}{$\mathrm{Au}$} & \multicolumn{2}{|c|}{ Ag } & \multicolumn{2}{|c|}{$\mathrm{Cu}$} & \multicolumn{2}{|c|}{ Pd } & \multicolumn{2}{|c|}{ Type IV Au Alloy } \\
\hline & & 0 & 2000 & 0 & 2000 & 0 & 2000 & 0 & 2000 & 0 & 2000 \\
\hline \multirow{2}{*}{ None } & & 8.3 & 1.0 & 8.7 & 2.0 & 9.1 & 2.1 & 9.2 & 2.0 & 7.6 & 1.4 \\
\hline & & $(1.0)^{a, A}$ & $(0.5)^{a, A}$ & $(1.2)^{a, A}$ & $(0.4)^{a, B}$ & $(1.5)^{a, A}$ & $(0.5)^{a, b}$ & $(1.5)^{\mathrm{a}, \mathrm{A}}$ & $(0.7)^{a b, b}$ & $(1.3)^{a, A}$ & $(0.6)^{\mathrm{a}, \mathrm{AB}}$ \\
\hline \multirow{2}{*}{ VP } & & 12.2 & 1.0 & 28.9 & 15.4 & 17.2 & 8.9 & 13.7 & 1.3 & 13.1 & 1.9 \\
\hline & & $(1.1)^{\mathrm{b}, \mathrm{A}}$ & $(0.4)^{\mathrm{a}, \mathrm{A}}$ & $(3.1)^{b, C}$ & $(1.8)^{c, C}$ & $(2.2)^{b, B}$ & $(1.6)^{c, B}$ & $(1.2)^{\mathrm{b}, \mathrm{A}}$ & $(0.5)^{\mathrm{a}, \mathrm{A}}$ & $(2.7)^{\mathrm{b}, \mathrm{A}}$ & $(1.0)^{a, A}$ \\
\hline \multirow{2}{*}{ MT } & & 13.7 & 1.9 & 26.5 & 7.6 & 23.2 & 8.7 & 15.1 & 2.0 & 20.7 & 1.7 \\
\hline & & $(2.7)^{\mathrm{b}, \mathrm{A}}$ & $(0.5)^{a, A}$ & $(3.7)^{b, C}$ & $(1.7)^{b, B}$ & $(2.6)^{\mathrm{c}, \mathrm{B}}$ & $(1.1)^{c, B}$ & $(2.4)^{\mathrm{b}, \mathrm{A}}$ & $(0.7)^{a b, A}$ & $(1.9)^{c, B}$ & $(0.7)^{\mathrm{a}, \mathrm{A}}$ \\
\hline \multirow{2}{*}{$\mathrm{AP}$} & & 11.8 & 2.0 & 28.6 & 13.3 & 25.5 & 6.2 & 13.3 & 1.7 & 10.5 & 1.3 \\
\hline & & $(1.4)^{\mathrm{b}, \mathrm{A}}$ & $(0.6)^{a, A}$ & $(3.7)^{b, C}$ & $(1.3)^{c, C}$ & $(2.3)^{\mathrm{C}, \mathrm{B}}$ & $(2.1)^{b, B}$ & $(1.2)^{\mathrm{b}, \mathrm{A}}$ & $(0.6)^{a b, A}$ & $(1.3)^{b, A}$ & $(0.5)^{a, A}$ \\
\hline \multirow{2}{*}{ MLP } & & 35.0 & 5.1 & 30.2 & 6.2 & 34.9 & 8.7 & 18.1 & 3.8 & 41.0 & 10.4 \\
\hline & & $(3.5)^{d, C}$ & $(1.6)^{\mathrm{b}, \mathrm{AB}}$ & $(2.7)^{b, B}$ & $(2.0)^{b, B}$ & $(2.9)^{d, C}$ & $(2.2)^{\mathrm{c}, \mathrm{C}}$ & $(2.5)^{c, A}$ & $(0.9)^{\mathrm{c}, \mathrm{A}}$ & $(3.7)^{d, D}$ & $(2.2)^{b, c}$ \\
\hline \multirow{2}{*}{ MPZ } & & 36.7 & 16.5 & 36.5 & 21.2 & 31.7 & 9.2 & 19.3 & 2.3 & 39.5 & 16.7 \\
\hline & & $(3.1)^{d, C}$ & $(2.2)^{c, C}$ & $(3.2)^{c, C}$ & $(3.1)^{d, D}$ & $(3.0)^{d, B}$ & $(1.8)^{\mathrm{c}, \mathrm{B}}$ & $(2.4)^{c, A}$ & $(0.6)^{b, A}$ & $(3.1)^{d, C}$ & $(1.7)^{\mathrm{c}, \mathrm{C}}$ \\
\hline \multirow{2}{*}{ MDTP } & & 26.2 & 14.2 & 34.6 & 23.7 & 17.9 & 3.3 & 18.4 & 2.4 & 37.5 & 10.9 \\
\hline & & $(3.7)^{c, B}$ & $(1.9)^{c, C}$ & $(3.2)^{c, C}$ & $(3.9)^{d, D}$ & $(1.5)^{\mathrm{b}, \mathrm{A}}$ & $(0.7)^{\mathrm{a}, \mathrm{A}}$ & $(1.7)^{\mathrm{c}, \mathrm{A}}$ & $(0.6)^{\mathrm{b}, \mathrm{A}}$ & $(4.3)^{d, C}$ & $(1.2)^{b, B}$ \\
\hline
\end{tabular}

Means with the same lowercase superscript letters are not significantly different within the same metal at each thermal cycle $(p>0.05)$; Means with the same uppercase superscript letters are not significantly different within the same primer at each thermal cycle $(p>0.05)$.

For the non-primed specimens at TC0, the bond strengths between the acrylic resin and pure metals were equal to approximately 8-9 MPa regardless of the metal type. On the other hand, when primed with one of the six metal primers, the bond strengths at TC0 were significantly higher than those obtained for the non-primed group $(p<0.05)$. At TC2000, the bond strengths between the acrylic resin and pure metals significantly decreased as compared to the corresponding values at TC0 regardless of the metal primer $(p<0.05)$. For Au and Ag primed with MPZ or MDTP, the bond strengths of the acrylic resin at TC2000 were significantly higher than the values obtained for the groups primed with the other four primers $(p<0.05)$. For $\mathrm{Cu}$ primed with MLP or MPZ, the bond strength at TC0 was more effectively improved among the six primers $(p<0.05)$. For Pd primed with MLP, MPZ, or MDTP, the bond strengths at TC 0 were higher than the values obtained for the other three primers $(p<0.05)$. However, the bond strength of the acrylic resin to Pd at TC2000 was not significantly different from the corresponding values obtained for the non-primed group, except for the MLP primer $(p>0.05)$.

When primed with one of the six metal primers, the bond strength between the self-cured acrylic resin and type IV Au alloy was found to be significantly higher than the value obtained for the non-primed group at TC0 $(p<0.05)$. However, at TC2000, the bond strengths were very similar to those obtained for the non-primed group, except for the MLP, MPZ, and MDTP primers $(p<0.05)$.

Table 4 shows the failure types for the fabricated resin-metal systems. All the non-primed specimens exhibited adhesive failures at the resin-metal interface regardless of the metal type or thermal cycling procedure (Figure 4a). In contrast, no adhesive failures were observed for the Au specimens primed with MPZ or MDTP and for type IV Au alloy primed with MLP, MPZ, or MDTP before and after TC, as indicated by the traces of the self-cured acrylic resin that remained on the metal surface (Figure 4b).

Table 4. Failure mode distribution in the experimental groups (number of specimens).

\begin{tabular}{ccccccccccccc}
\hline \multirow{2}{*}{ Primer } & Metal & \multicolumn{2}{c}{ Au } & \multicolumn{2}{c}{ Ag } & \multicolumn{2}{c}{ Cu } & \multicolumn{3}{c}{ Pd } & \multicolumn{3}{c}{ Type IV Au Alloy } \\
\cline { 2 - 12 } & Cycles & $\mathbf{0}$ & $\mathbf{2 0 0 0}$ & $\mathbf{0}$ & $\mathbf{2 0 0 0}$ & $\mathbf{0}$ & $\mathbf{2 0 0 0}$ & $\mathbf{0}$ & $\mathbf{2 0 0 0}$ & $\mathbf{0}$ & $\mathbf{2 0 0 0}$ \\
\hline None & & A10 & A10 & A10 & A10 & A10 & A10 & A10 & A10 & A10 & A10 \\
VP & & M10 & A10 & M10 & M10 & M10 & A10 & M10 & A10 & M10 & A10 \\
MT & & M10 & A10 & M10 & A10 & M10 & A10 & M10 & A10 & M10 & A10 \\
AP & & M10 & A10 & M10 & M10 & M10 & A10 & M10 & A10 & M10 & A10 \\
MLP & & M10 & A10 & M10 & A10 & M10 & A10 & M10 & A10 & M10 & M10 \\
MPZ & M10 & M10 & M10 & M10 & M10 & A10 & M10 & A10 & M10 & M10 \\
MDTP & M10 & M10 & M10 & M10 & M10 & A10 & M10 & A10 & M10 & M10 \\
\hline
\end{tabular}

A: adhesive failure at the metal-acrylic resin interface, M: mixed failure of the adhesive failure at the metal-acrylic resin interface and the cohesive failure of acrylic resin. 


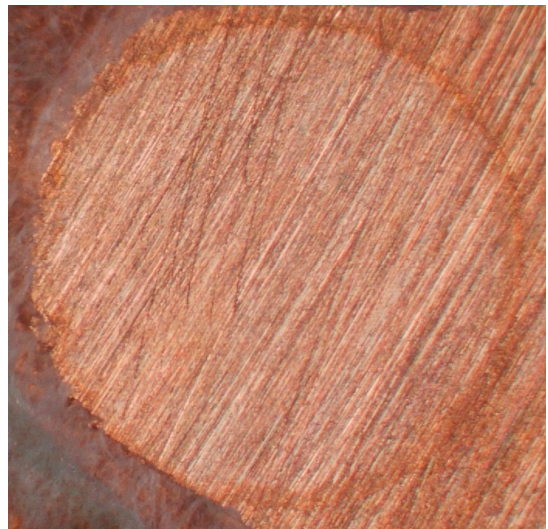

(a)

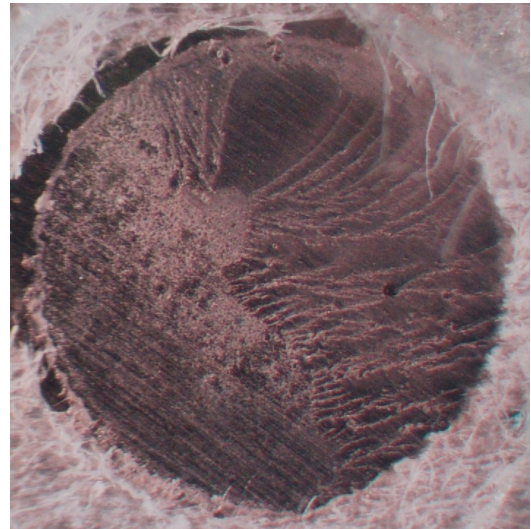

(b)

Figure 4. Microscopy image $(\times 45)$ representative failure. (a) adhesive failure at Au-self-cured acrylic resin interface, (b) mixed failure of the adhesive failure at Au alloy-self-cured acrylic resin interface and the cohesive failure of self-cured acrylic resin.

Figure 5 shows the wide scan XPS spectrum peaks with the energy values corrected with respect to the $\mathrm{C} 1$ s peak $(284.8 \mathrm{eV})$. The XPS analysis revealed the presence of $\mathrm{Au}, \mathrm{Cu}, \mathrm{Ag}, \mathrm{Pt}, \mathrm{O}, \mathrm{C}$, and $\mathrm{N}$ elements

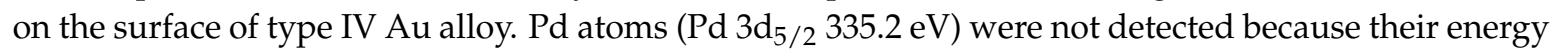
peaks were very close to the Au ones ( $\mathrm{Au} 4 \mathrm{~d}_{2 / 5} 334.8 \mathrm{eV}$, it was also difficult to detect small amounts of $\mathrm{Pd}$ when large amounts of Au were present). According to the obtained XPS binding energies, the Au and $\mathrm{Pt}$ (Figure 6, upper panel) as well as $\mathrm{Ag}$ (Figure 6, center) elements were present in their metal states, while the $\mathrm{Cu}$ element (Figure 6, lower panel) was present both in its metal state $(932.7 \mathrm{eV})$ and as $\mathrm{Cu}_{2} \mathrm{O}(932.4 \mathrm{eV}$, their corresponding binding energies were very close). In addition, small amounts of $\mathrm{CuO}(933.8 \mathrm{eV})$ were detected as well.

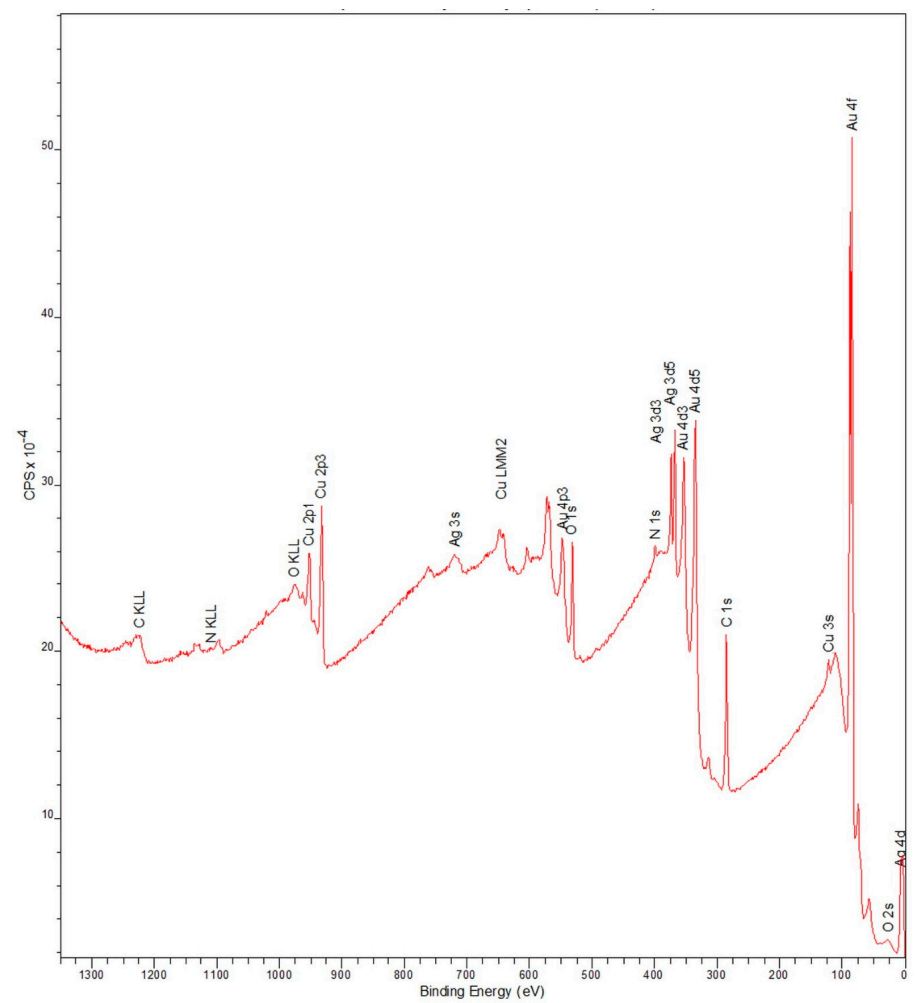

Figure 5. X-ray photoelectron spectroscopy (XPS) spectra for type IV Au alloy. 

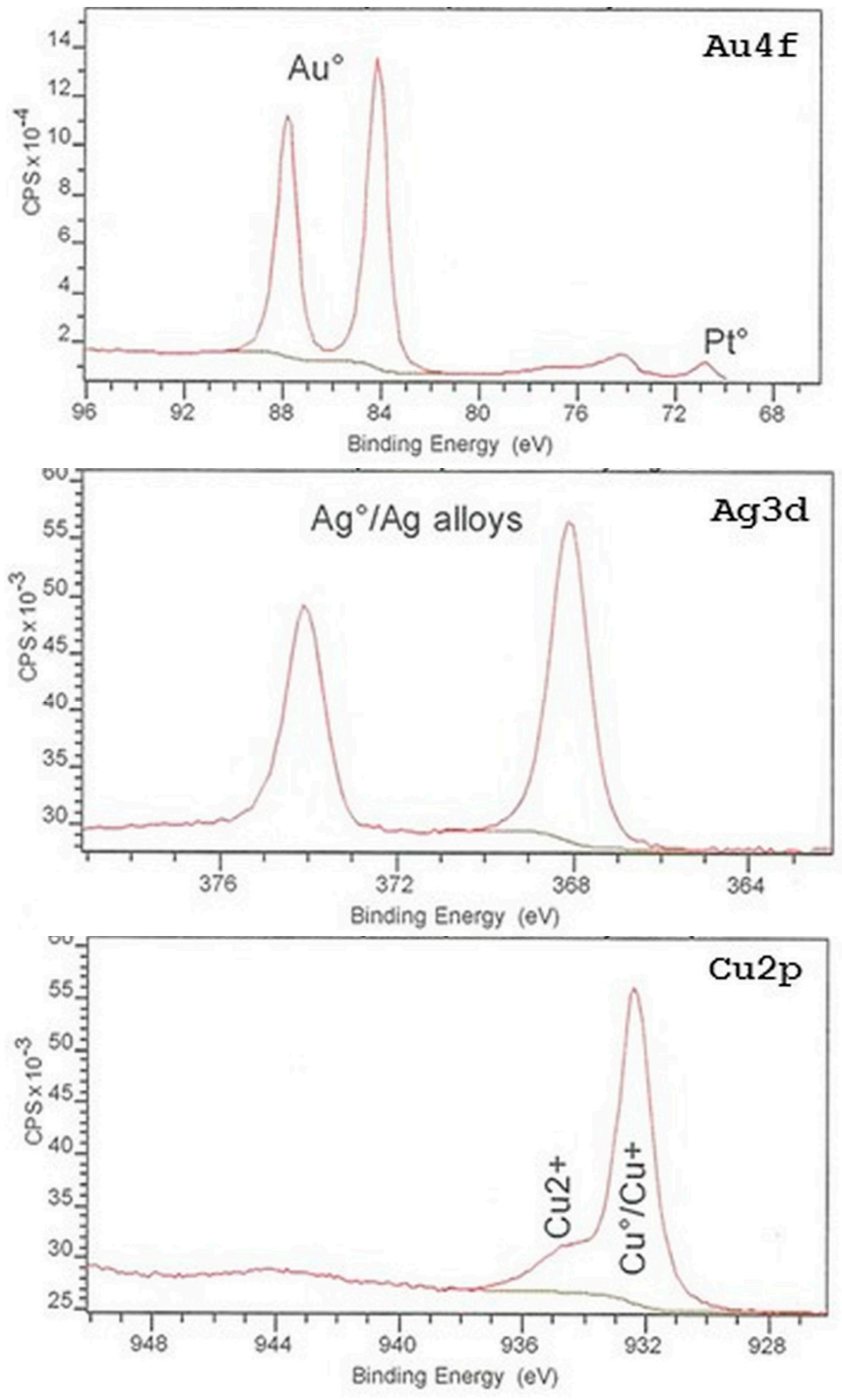

Figure 6. X-ray photoelectron spectroscopy (XPS) spectra of Au4f, Ag3d, and Cu2p for type IV Au alloy.

\section{Discussion}

The bond strengths of the self-cured acrylic resin to the four pure metals primed with one of the six sulfur-containing metal primers increased significantly as compared to the non-primed group at TC0 $(p<0.05)$. However, at TC2000, the bond strengths between the resin and the five metals significantly decreased with respect to the values obtained at TC0 regardless of the primer $(p<0.05)$. The sulfur-containing metal primers, except for Metal Link Primer, were more effective for improving the bond strength between the self-cured acrylic resin and Ag as compared to the other three pure metals $(p<0.05)$.

Shear bond strength testing has been conducted in previous studies because the presence of non-uniform interfacial stress may cause cohesive failures of the bonding substrate and misinterpretation of the obtained data [22]. In addition, the stress concentration near the loading site reduced the calculated value of the shear bond strength below the true failure stress level [23]. In the current study, adhesive failures were mainly observed at TC2000, except for Ag primed with VP, AP, MPZ, or MDTP primer; Au primed with MPZ or MDTP primer; and type IV Au alloy primed with MLP, MPZ, or MDTP primer (no cohesive failures occurred in the self-cured acrylic resin). Hence, it appeared possible to evaluate the effect produced by several metal primes on the bonding of the self-cured resin to noble metals after TC via shear testing. 
TC was used as a standard procedure for simulating the aging process [13-21]. It utilizes the differences in the thermal coefficients of the expansion of the metal and acrylic resin, which induce stress in the adhesive bonding of various functional monomers contained in the utilized primers to the studied metal surfaces. Although it is not possible to fully simulate the environment inside the oral cavity under laboratory conditions, including the moisture and stress induced at the interface between the teeth and the restorations, laboratory conditions can, to some extent, simulate the oral cavity environment through the aging procedure. Among various laboratory processes that are capable of reproducing dynamic stress, TC represents one of the most widely used aging methods, and it is often referenced in the literature [24]. Temperature changes inside the oral cavity are dynamic in nature; thus, it is very hard to define the temperature range corresponding to the mouth physiology. It has been reported previously that the TC temperatures commonly utilized by researchers were too extreme to provide a representative simulation of the temperature fluctuations in vivo [25]. However, the range between $4{ }^{\circ} \mathrm{C}$ and $60^{\circ} \mathrm{C}$ used in this study was adopted as a reference, which was in partial agreement with the ISO 11405 recommendations [26], and allowed evaluation of the intraoral temperature ranges in vivo [27].

Generally, when metal primers are used clinically, adhesive resin cements containing effective promoting monomers are prepared for luting restorations. When used with Super-Bond C\&B as luting cement, its bond strengths to $\mathrm{Au}, \mathrm{Ag}$, and $\mathrm{Cu}$ without metal primers exceeded $35 \mathrm{MPa}$ [28], which were much higher than the values obtained in our study. Since it is difficult to evaluate the effectiveness of primers for noble metals when adhesive resin cement is used, self-cured acrylic resin without functional monomers was prepared in this study. The internal surfaces of metal restorations are usually alumina-blasted by dental laboratories after casting to remove the reaction layers of the investment material. In this study, the surfaces of the tested metal specimens were only polished with Si carbide paper in order to reduce the mechanical retention of the self-cured acrylic resin as compared to the alumina-blasted specimens, although even the polishing of the metal surface with $\mathrm{Si}$ carbide paper was unable to completely eliminate the mechanical retention. Thus, the effectiveness of the utilized metal primers has been evaluated adequately in this work.

VBATDT has been synthesized as a sulfur-containing monomer [11], which significantly enhanced the bond strength and bonding durability of the Ag and $\mathrm{Cu}$ surfaces [12,13]. In addition, improved bond strength was also reported for the Pd and Au metals [12,29]. VBATDT is chemisorbed via sulfur atoms on the $\mathrm{Au}, \mathrm{Ag}$, and $\mathrm{Cu}$ surfaces, assuming a triazine dithiol-type ring structure [30]. In this study, the VBATDT-containing VP and AP primers and the MT primer were more effective for Ag at TC 0 and TC2000 as compared to the other four metals. On the other hand, the MLP primer was more effective for $\mathrm{Au}, \mathrm{Ag}, \mathrm{Cu}$, and type IV alloy at TC0 as compared to Pd; while at TC2000, higher bond strengths were observed for $\mathrm{Cu}$ and type IV Au alloy as compared to the values obtained for the other three metals. The MDTP-containing MPZ primer was more effective for Au and Ag than for $\mathrm{Cu}$ and Pd at TC0 and TC2000. Thus, MDTP was found to be effective for improving the bond strength of the resin to pure $\mathrm{Au}$ and $\mathrm{Ag}$. The sulfur-containing monomers contained in the five commercially available metal primers differed in their chemical structures, which might influence the strength of the chemical bonding to the noble metal surfaces. Therefore, the bonding durability of the self-cured acrylic resin to the noble metals depended on the utilized metal primer brand.

For the pure $\mathrm{Au}, \mathrm{Ag}, \mathrm{Cu}$, and $\mathrm{Pd}$ evaporated onto glass substrates, the $\mathrm{Au}$ and $\mathrm{Pd}$ elements were present in their metal states, while the $\mathrm{Ag}$ and $\mathrm{Cu}$ elements were detected by XPS in the forms of $\mathrm{Ag}_{2} \mathrm{O}$, $\mathrm{Cu}_{2} \mathrm{O}$, and $\mathrm{CuO}$ oxides [31]. In this study, the $\mathrm{Au}, \mathrm{Ag}, \mathrm{Pd}$, and Pt elements were present on the surface of type IV Au alloy in their metal states, while the $\mathrm{Cu}$ element was detected both in its metal state and as small amounts of $\mathrm{Cu}_{2} \mathrm{O}$ and $\mathrm{CuO}$ oxides, as determined by XPS (Figures 5 and 6). It was found that the sulfur-containing monomers did not react with the oxide layers that were formed on base metal surfaces in the atmospheric environment [32]. On the other hand, the chemical adsorption of organic sulfur-containing compounds was observed on the Au surface followed by the formation of monolayer films, which resulted in their chemical interaction with the Au surface atoms [30]. Therefore, 
each sulfur-containing monomer contained in the utilized metal primers might form chemical bonds with predominantly Au metal atoms on the type IV Au alloy surface, thus leading to their adhesion. However, the durability of the chemical bonding with the Au atoms depended on the metal primer brand. Among the studied sulfur-containing monomers, the MPZ primer exhibited the highest bonding durability of the resin to pure Au and type IV Au alloy.

The VBATDT-containing AP primer or the MDTP-containing MPZ primer was more effective for $\mathrm{Cu}$ than the VP or MDTP primers, respectively. It should be noted that both the AP and MPZ primers contain MDP in addition to the VBATDT and MDTP monomers, respectively. Moreover, among the six metal primers, the highest bond strength between the resin and $\mathrm{Cu}$ at TCO was obtained with the MLP primer. MLP contains 6-MHPA phosphoric acid monomer, which is very similar to MDP, while both MDP and 6-MHPA exhibit affinity to the oxide layer generated on the metal surface [18,21]. Therefore, both MDP and 6-MHPA may react with the $\mathrm{Cu}$ oxide layer that is formed on the surface of pure $\mathrm{Cu}$.

\section{Conclusions}

The sulfur-containing metal primers, except for Metal Link Primer, more effectively improved the bond strength between the self-cured acrylic resin and $\mathrm{Ag}$ as compared to $\mathrm{Au}, \mathrm{Cu}$, and $\mathrm{Pd}$. The bonding durability depended on the utilized metal primer brand. The MDTP-containing MPZ primer was preferable for type IV Au alloy, because it bonded the self-cured acrylic resin to the predominant Au surface atoms most efficiently.

Conflicts of Interest: The author declares no conflict of interest.

\section{References}

1. Tanaka, T.; Nagata, K.; Takeyama, M.; Atsuta, M.; Nakabayashi, N.; Masuhara, E. 4-META opaque resin-A new resin strongly adhesive to nickel-chromium alloy. J. Dent. Res. 1981, 60, 1697-1706. [CrossRef] [PubMed]

2. Yamashita, A.; Kondo, Y.; Fujita, M. Adhesive strength of adhesive resin PANAVIA EX to dental alloys. Part 2. Adhesive strength of precious alloys. J. Jpn. Prosthodont. Soc. 1984, 28, 1023-1033. [CrossRef]

3. Watanabe, F.; Powers, J.M.; Lorey, R.E. In Vitro bonding of prosthodontic adhesives to dental alloys. J. Dent. Res. 1988, 67, 479-483. [CrossRef] [PubMed]

4. Imbery, T.A.; Davis, R.D. Evaluation of tin plating systems for a high-noble alloy. Int. J. Prosthodont. 1993, 6, 55-59. [PubMed]

5. Gates, W.D.; Diaz-Arnold, A.M.; Aqilino, S.A.; Ryther, J.S. Comparison of the adhesive strength of a BIS-GMA cement to tin-plated and non-tin-plated alloys. J. Prosthet. Dent. 1993, 69, 12-16. [CrossRef]

6. Rubo, J.H.; Pegoraro, L.F.; Ferreira, P.M. A comparison of tensile bond strengths of resin-retained prostheses made using five alloys. Int. J. Prosthodont. 1996, 9, 277-281. [PubMed]

7. Swartz, J.M.; Davis, R.D.; Overton, J.D. Tensile bond strength of resin-modified glass-ionomer cement to microabraded and silica-coated or tin-plated high noble ceramic alloy. J. Prosthodont. 2000, 9, 195-200. [CrossRef] [PubMed]

8. Tanaka, T.; Atsuta, M.; Nakabayashi, N.; Masuhara, E. Surface treatment of gold alloys for adhesion. J. Prosthet. Dent. 1988, 60, 271-279. [CrossRef]

9. Ohno, H.; Araki, Y.; Endo, K. A new method for promoting adhesion between precious metal alloys and dental adhesives. J. Dent. Res. 1992, 71, 1326-1331. [CrossRef] [PubMed]

10. Stokholm, R.; Isidor, F.; Ravnholt, G. Tensile bond strength of resin luting cement to a porcelain-fusing noble alloy. Int. J. Prosthodont. 1996, 9, 323-330.

11. Mori, K.; Nakamura, Y. Study on triazine thiols. V. Polymerization of 6-(4-vinylbenzyl propyl) amino-1,3,5-triazine-2,4-dithiol on copper plates and their corrosion resitance. J. Polym. Sci. Polym. Lett. Ed. 1983, 21, 889-895. [CrossRef]

12. Kojima, K. Studies on adhesion of functional monomers with $\mathrm{SH}$ group to tooth substrates and dental alloys. J. Jpn. Soc. Dent. Mater. Devices 1986, 5, 92-105. 
13. Kojima, K.; Kadoma, Y.; Imai, Y. Adhesion to precious metals utilizing triazine dithione derivative monomer. J. Jpn. Soc. Dent. Mater. Devices 1987, 6, 702-707.

14. Taira, Y.; Imai, Y. Primer for bonding resin to metal. Dent. Mater. 1995, 11, 2-6. [CrossRef]

15. Yoshida, K.; Kamada, K.; Tanagawa, M.; Atsuta, M. Shear bond strengths of three resin cements used with three adhesive primers for metal. J. Prosthet. Dent. 1996, 75, 254-261. [CrossRef]

16. Yoshida, K.; Kamada, K.; Sawase, T.; Atsuta, M. Effect of three adhesive primers for a noble metal on the shear bond strength of three resin cements. J. Oral Rehabil. 2001, 28, 14-19. [CrossRef] [PubMed]

17. Taira, Y.; Kamada, K. Effects of primers containing sulfur and phosphate monomers on bonding type IV gold alloy. J. Dent. 2008, 36, 595-599. [CrossRef] [PubMed]

18. Ikemura, K.; Fujii, T.; Negoro, N.; Endo, T.; Kadoma, Y. Design of a new metal primer containing a dithiooctanoate monomer and a phosphoric acid monomer for bonding prosthetic light-curing resin composite to gold, dental precious and non-precious metal alloys. Dent. Mater. J. 2011, 30, 300-307. [CrossRef] [PubMed]

19. Choo, S.-S.; Huh, Y.-H.; Cho, L.-R.; Park, C.-J. Effect of metal primers and tarnish treatment on bonding between dental alloys and veneer resin. J. Adv. Prosthodont. 2015, 7, 392-399. [CrossRef] [PubMed]

20. Piva, E.; Azevedo, E.C.; Ogliari, A.O.; Pilownic, K.J.; Pinto, M.B.; Camacho, G.B.; Petzhold, C.L.; Ogliari, F.A. Evaluation of experimental phosphate and sulfur-based primer bonding to metal casting alloys. Int. J. Adhes. Adhes. 2015, 58, 59-62. [CrossRef]

21. Ikemura, K.; Endo, T.; Kadoma, Y. A review of the developments of multi-purpose primers and adhesives comprising novel dithiooctanoate monomers and phosphoric acid monomers. Dent. Mater. J. 2012, 31, 1-25. [CrossRef] [PubMed]

22. Della Bona, A.; Anusavice, K.J.; Hood, J.A. Effect of ceramic surface treatment on tensile bond strength to a resin cement. Int. J. Prosthodont. 2002, 15, 248-253. [PubMed]

23. Van Noort, R.; Noroozi, S.; Howard, I.C.; Cardew, G. A critique of bond strength measurements. J. Dent. 1989, 17, 61-67. [CrossRef]

24. Morresi, A.L.; D'Amario, M.; Capogreco, M.; Gatto, R.; Marzo, G.; D'Arcangelo, C.; Monaco, A. Thermal cycling for restorative materials: Does a standard protocol exist in laboratory testing? A literature review. J. Mech. Behav. Biomed. Mater. 2014, 29, 295-308. [CrossRef] [PubMed]

25. Gale, M.S.; Darvell, B.W. Thermal cycling procedures for laboratory testing of dental restorations. J. Dent. 1999, 27, 89-99. [CrossRef]

26. International Standard Organization. Guidance on Testing of Adhesion to Tooth Structure. ISO/TR 11405 Dental Materials; ISO: Geneva, Switzerland, 1994; pp. 1-14.

27. Kamada, K.; Tanaka, T.; Watanabe, I.; Uematsu, R.; Tanagawa, M.; Yoshida, K.; Matsumura, H.; Atsuta, M. Temperature change on the interface of adhesive retained prosthesis when taking foods. J. Jpn. Soc. Dent. Mater. Devices 1995, 14, 578-583.

28. Okuya, N.; Minami, H.; Kurashige, H.; Murahara, S.; Suzuki, S.; Tanaka, T. Effects of metal primers on bonding of adhesive resin cement to noble alloys for porcelain fusing. Dent. Mater. J. 2010, 29, 177-187. [CrossRef] [PubMed]

29. Kadoma, Y.; Kojima, K.; Tamaki, Y.; Nomura, Y. Water durability of resin bond to pure gold treated with various adhesion promoting thiirane monomers. Dent. Mater. J. 2007, 26, 29-37. [CrossRef] [PubMed]

30. Suzuki, M.; Yamamoto, M.; Fujishima, A.; Miyazaki, T.; Hisamitsu, H.; Kojima, K.; Kadoma, Y. Raman and IR studies on absorption behavior of adhesive monomers in a metal primer for $\mathrm{Au}, \mathrm{Ag}, \mathrm{Cu}$ and $\mathrm{Cr}$ surfaces. J. Biomed. Mater. Res. 2002, 62, 37-45. [CrossRef] [PubMed]

31. Echizenya, T. Interfaces of Metals and 4-META/MMA-TBBO resin. J. Jpn. Soc. Dent. Mater. Devices 1992, 11, 628-641.

32. Ohno, H.; Araki, Y.; Segara, M. The adhesion mechanism of dental adhesive resin to the alloy-Relationship between Co-Cr alloy surface structure analyzed by ESCA and bonding strength of adhesive resin. Dent. Mater. J. 1986, 5, 46-65. [CrossRef] [PubMed]

(C) 2017 by the author. Licensee MDPI, Basel, Switzerland. This article is an open access article distributed under the terms and conditions of the Creative Commons Attribution (CC BY) license (http://creativecommons.org/licenses/by/4.0/). 